\title{
La potestad autonormativa en relación con los estatutos del personal de los parlamentos autonómicos
}

\section{Autonomous authority in relation to the staff regulations of autonomous parliaments}

\author{
Rafael Cano Silva \\ Parlamento de Andalucía \\ r.cano@parlamento-and.es
}

\begin{abstract}
NOTA BIOGRÁFICA
Doctor en Derecho Administrativo por la Universidad de Sevilla, Licenciado en Ciencias del Trabajo y Diplomado en Relaciones Laborales por la citada Universidad. Máster en Derecho Público. Funcionario del Cuerpo Técnico del Parlamento de Andalucía. En sus principales líneas de investigación están los Problemas actuales del Derecho Administrativo, en concreto la función pública parlamentaria. Publicaciones principales: "La participación directa de los promotores de las Iniciativas Legislativas Populares en su tramitación en las Comunidades Autónomas: El caso particular de la Comunidad Autónoma de Andalucía" (Revista andaluza de Administración Pública); "La mujer en el Parlamento de Andalucía: 30 años de representación política" (Publicación de I Congreso internacional sobre sustentabilidad, competitividad y género en las organizaciones); "El control político del Parlamento de Andalucía de las contabilidades de los Grupos parlamentarios y la financiación de los Partidos políticos" (Revista de Estudios de la Administración Local y Autonómica); "El mercado de trabajo femenino en Andalucía: La visión de la Cámara andaluza a lo largo de nueve legislaturas" (Revista Aequalitas: Revista Jurídica de igualdad de oportunidades entre mujeres y hombres).
\end{abstract}

\section{RESUMEN}

Los Estatutos del Personal de los Parlamentos autonómicos son normas administrativas parlamentarias aprobadas por cada cámara legislativa en virtud de su autonomía parlamentaria. No obstante, la autonomía parlamentaria de cada Parlamento autonómico no dispone de la misma competencia normativa a estos efectos. Se estudia en este artículo, como a pesar de contar con la Constitución como elemento común, es fundamental la atribución especial con la que cuenta cada Cámara autonómica y que la jurisprudencia, tanto del Tribunal Constitucional, como la del Tribunal Supremo, ha puesto en valor; cuestión que se recoge en el epígrafe relativo a la jurisprudencia. En conclusión, la organización burocrática, en lo que se refiere a los medios personales, podrá ser sustancialmente diferente en las distintas Asambleas Legislativas, tal como se analiza en las conclusiones de este estudio.

\section{PALABRAS CLAVE}

Estatuto de autonomía, funcionarios.

\begin{abstract}
The statutes of Autonomous Parliaments are parliamentary administrative norms approved by each legislative chamber by virtue of their parliamentary autonomy. However, the parliamentary autonomy of each autonomous parliament does not have the same normative aspect for these purposes. It is studied in this article as despite having the Constitution as a common element, it is essential the special attribution that each autonomous chamber has and that the jurisprudence, both of the Constitutional Court, and that of
\end{abstract}


the Supreme Court, has put in value, question that is included in the section related to the jurisprudence. In conclusion, the bureaucratic organization, in what refers to personal media, may be substantially different in each one of the legislative assemblies, as analyzed in the conclusions of this study.

\section{KEYWORDS}

Statute of Autonomy, civil servants.

\section{SUMARIO}

1. BREVE INTRODUCCIÓN. 2. JUSTIFICACIÓN DE LA AUTONOMÍA EN MATERIA DE PERSONAL. 3. LA POTESTAD NORMATIVA COMO PARTE DE LA AUTONOMÍA ADMINISTRATIVA EN MATERIA DE PERSONAL. 4. REGULACIÓN EN LA CONSTITUCIÓN ESPAÑOLA. 5. REGULACIÓN AJENA A LA CONSTITUCIÓN ESPAÑOLA. 6. LA JURISPRUDENCIA CONSTITUCIONAL Y DEL TRIBUNAL SUPREMO RELATIVA A LA COMPETENCIA NORMATIVA DE LAS ASAMBLEAS LEGISLATIVAS EN RELACIÓN CON SUS ESTATUTOS DEL PERSONAL. 7. CONCLUSIONES. 8. REFERENCIAS BIBLIOGRÁFICAS.

\section{BREVE INTRODUCCIÓN}

El ordenamiento jurídico español ha optado en la actualidad por una organización política basada en la división de poderes. En tal sentido, lo establece tanto la Constitución como los Estatutos de Autonomía (en adelante, EE.AA) de las Comunidades Autónomas (en adelante, CC.AA).

De acuerdo con dicha línea, las cámaras parlamentarias deben funcionar con absoluta independencia frente a los otros poderes. A tales efectos, disponen de una organización burocrática, compuesta tanto de medios materiales (incluidos los patrimoniales), como de medios personales, al objeto de realizar las funciones auxiliares necesarias para el desempeño de las funciones institucionales que las Asambleas Legislativas tienen encomendadas.

Este funcionamiento con absoluta independencia frente a los otros poderes se consigue gracias a la autonomía parlamentaria, entendiéndose por la misma el «conjunto de facultades que disponen los parlamentos para regular y gestionar ellos mismos las actuaciones que realizan en el ejercicio de sus funciones sin injerencia de otros Órganos e Instituciones» (MARTíNEZ y VISIEDO, 2008: 94) y (MARTíNEZ y VISIEDO, 2009: 147).

La autonomía en materia de personal es una concreción de la autonomía parlamentaria en la vertiente autoorganizativa y autonormativa. Implica necesariamente la dotación de un conjunto de normas propias. Esta autonomía asegura el adecuado desarrollo de las funciones peculiares y diferentes fines por los medios personales de la Cámara y que difieren de la Administración pública.

\section{JUSTIFICACIÓN DE LA AUTONOMÍA EN MATERIA DE PERSONAL}

Precisamente los fines específicos que se encomiendan a las cámaras parlamentarias son los que justifican determinadas especialidades normativas en relación con la peculiaridad de los trabajos parlamentarios, constituyendo, de este modo, un ejemplo de la autonomía administrativa y normativa en materia de personal que presta sus servicios en las Asambleas Legislativas y concretamente en la Administración parlamentaria.

Es decir, a pesar de que esta vertiente administrativa de la autonomía parlamentaria es meramente instrumental, es imprescindible para llevar a cabo los fines institucionales de las Cámaras legislativas autonómicas, ya que, aunque per se, los fines instrumentales no entran en dicho ámbito, pueden influir en ellos.

No obstante, a pesar de que la inmensa mayoría de los preceptos, que conforman el contenido del estatuto jurídico de la función pública de las Asambleas Parlamentarias, son reproducciones de los ya existentes en la función pública de la Administración pública, no por ello podemos pensar que negativiza la autonomía parlamentaria en esta materia, más al contrario, pues este mimetismo es en función de la propia voluntad de la Cámara legislativa.

Cuestión diferente puede constituir la posible falta de innovación legislativa y de ideas de la función pública parlamentaria, que se limita de una manera pobre a reproducir estructuras, modelos y normas de la función pública administrativa (entendida esta en el sentido formal), en vez de crear una auténtica función 
pública parlamentaria sui generis acorde con la dimensión más reducida, acceso del personal, promoción y carrera administrativa, movilidad funcionarial, formación, creación de estructuras y órganos más dinámicos de unas administraciones parlamentarias que deben dar respuestas ágiles a las diversas cuestiones que se planteen en el cotidiano trabajo parlamentario, sin cargar con los esquemas tradicionales de la pesada y lenta maquinaria de la Administración pública.

Las funciones específicas y el desarrollo de las mismas exigen un funcionariado específico y diferente del funcionario común (de la Administración pública). De este modo, TUDELAARANDA afirma que "[...] para la consecución de los fines políticos que le han sido encomendados, es del todo preciso que disponga de la suficiente cobertura de medios personales y materiales" (TUDELA, 2011:159). La importancia de esta cuestión no es baladí, hasta el punto de que alguna doctrina ha llegado a hablar de la necesidad de singularizar una función administrativo-parlamentaria que debería revalorizarse. (BLANCO, 2002: 157)

A mayor abundamiento, diremos que, esa autonomía del personal de las cámaras autonómicas no solo persiguen la imposibilidad de injerencia del Poder Ejecutivo (en la ya archiconocida antinomia o antítesis Poder Ejecutivo versus Poder Legislativo) sino que también busca la independencia de las mismas en relación con otros poderes no externos a la misma como constituyen los Grupos parlamentarios, al objeto de garantizar la máxima neutralidad y objetividad en los servicios a estos y a sus Diputados.

Estas funciones instrumentales, a las que hemos hecho referencia, son justificadas, a la vez, por una mejor adaptación a las funciones peculiares de las Asambleas Legislativas, tan diferentes, en la mayoría de los casos a las que conforman las Administraciones públicas, si bien, no por ello, no menos comunes a ellas.

En otras palabras, habrá materias que no sean comunes a las de la Administración pública, por ejemplo retribuciones de los diputados, procedimientos administrativos especiales relativos a la elaboración de acuerdos sobre tramitación legislativa o de nombramientos de personas de extracción parlamentaria, pero habrá otros, que pese a ser común a la Administración pública, como es el caso de la gestión del personal, es diferente, en la medida que la organización requerida para el desarrollo de las funciones parlamentarias, exigen cuerpos del personal diferentes, así como las relaciones de puestos de trabajo, horarios característicos, evaluación y desempeño de los puestos de la Administración parlamentaria que no podrán ser iguales a otro tipo de Administración, e incluso, responsabilidades diferentes. Sirva a modo de ejemplo, las actividades consultivas, como las jurídicas, entre las que hay que mencionar las asesorías técnicas de Comisiones parlamentarias, las realizadas en el seno del procedimiento legislativo, especialmente las relativas a calificación de enmiendas por las Mesas de las Comisiones, las relativas a las Comisiones de investigación o las actuaciones realizadas ante la jurisdicción constitucional. Otras, de tipo consultivo, son las de carácter económico, como en el apoyo realizado para la elaboración del presupuesto, o petición de información contable al Ejecutivo realizado por los diputados y grupos parlamentarios, gestiones administrativas de contratación y patrimoniales. Y para finalizar con las actividades consultivas, las lingüísticas y de redacción, siendo relevantes las primeras de las mencionadas en los parlamentos bilingües ${ }^{1}$.

Si bien, hay parte de la doctrina, tal es el caso de TUDELA ARANDA que únicamente justifica la autonomía administrativa de las cámaras en cuánto sea necesaria para garantizar la autonomía política. Consecuencia de ello, este autor no aprecia motivos para que existan "[...] determinadas singularidades del régimen jurídico de sus funcionarios o de otras materias propias de la organización administrativa" (TUDELA, 2008: 281). Pero, a la vez, afirma que "Existen rasgos específicos del actuar parlamentario que justifican y explican diferencias razonables, sobre todo en relación con el régimen jurídico de su personal» (TUDELA, 2008: 282).

La dotación de normas que constituyen la función pública parlamentaria por las propias cámaras parlamentarias se justifica, como dice MURO, en que «si el parlamento puede determinar el estatuto de la función pública no parlamentaria, en la medida que lo regula por ley, a la que deberá subordinarse el ulterior desarrollo normativo por quien corresponda, puede, con mayor razón, ordenar su propio personal, sin otro límite que la Constitución.» (MURO, 2009: 212).

Lo que hemos de entender por función pública parlamentaria engloba, tal como hemos afirmado, las especificidades del personal al servicio, tanto de las Cortes Generales, como de las Asambleas Le-

\footnotetext{
1 Otros tipos de actividades son las de gestión como las publicaciones parlamentarias y documentación parlamentarias para la formación de la voluntad de las Cámaras, actividades de ejecución, etc. Véase para mayor explicitación y concreción de las materias auxiliares objeto de las cámaras parlamentarias a SARMIENTO MÉNDEZ, X. A. (2009): "La función pública parlamentaria y su plasmación legislativa en Galicia", Corts: anuario de Derecho Parlamentario, 22: 254-257.
} 
gislativas de las CC.AA, si bien, no existe unanimidad en la definición del personal funcionario de las diferentes cámaras autonómicas y las Cortes Generales; extremo que señala SERRANO RUIZ. (SERRANO, 2006: 156.)

La justificación concreta de la autonomía de personal de las cámaras parlamentarias, de conformidad con lo que se ha ido exponiendo en este epígrafe, se traduce en las mismas cuestiones que fundamentan la autonomía parlamentaria, es decir, en la independencia de estos Parlamentos frente a los demás poderes (ello conlleva que las necesidades administrativas que deben ser satisfechas por las Cámaras, lo sean a través de su propio personal sometido a sus normas e instrucciones, evitando, por tanto, que las tareas administrativas necesarias para llevar a cabo las funciones parlamentarias sean realizadas por funcionarios públicos de otras instituciones).

Si bien, como afirma PÉREZ SERRANO, "[...] no se trata pues de una ley privada que autorice excepcionalmente a persona o clase para gozar de un régimen singular y al margen de la ley; se trata de una normación especial, impuesta por la naturaleza de la institución y necesaria para que llene cumplidamente sus fines" (PÉREZ, 1976: 770).

Con independencia del enfoque teórico expuesto hasta aquí, hemos de exponer también el fundamento práctico, resultado del día a día del funcionamiento cotidiano de las Cámaras, que se traduce en la naturaleza especial del trabajo parlamentario así como la disponibilidad y cualificación específica que deben reunir los empleados públicos parlamentarios, lo que justifica un cuadro jurídico regulador distinto al resto del personal y que abarca fundamentalmente la selección, retribución, organización y régimen disciplinario propios $^{2}$.

\section{LA POTESTAD NORMATIVA COMO PARTE DE LA AUTONOMÍA ADMINISTRATIVA EN MATERIA DE PERSONAL}

Al hablar de la autonomía administrativa en materia de personal o, incluso, de la función pública parlamentaria, se debe entender en un sentido amplio, como aglutinador de los diferentes regímenes jurídicos que regulan las clases de personal que prestan sus servicios en las cámaras parlamentarias.

Esta función pública parlamentaria es consecuencia de la autonomía administrativa de estas Asambleas Legislativas, motivada por la necesidad de autogestionar sus propios medios personales para poder realizar con independencia sus fines instituciones que constitucional y/o estatutariamente les corresponden a los Parlamentos.

Es, consecuentemente, la autonomía en materia de personal una manifestación del principio de autonomía parlamentaria, pues comparte el mismo fundamento, como es la salvaguarda de la independencia de la cámara frente al Poder Ejecutivo fundamentalmente, si bien, es una facultad instrumental respecto a los fines institucionales que tiene asignados pues se exige que las condiciones en las que se adoptan las decisiones de las Cámaras sean de independencia real.

La capacidad de autogestión de su personal, a la que nos hemos referido en el párrafo anterior, es amplia. Abarca la selección, la dirección y organización e, incluso, sanción, y si es necesario, la extinción de la relación administrativa del mismo.

Pero esa capacidad no es la misma que la reconocida a otras instituciones como la Administración autonómica, entes locales o universidades, sino que es una competencia normativa que aprueba el propio Parlamento; el Poder público sobre el que descansa la competencia legislativa, de ahí que, en muchos casos, esta capacidad normativa se traduzca en capacidad legislativa para la regulación de su propio personal.

En definitiva, estamos intentando reflejar la importancia esencial de la autonomía parlamentaria en la que se fundamenta la elaboración y aprobación de los EE.PP. Por ello, a tal fin, la autonomía administrativa de las cámaras parlamentarias debe englobar la potestad normativa plena.

\footnotetext{
2 Además de la autonomía e independencia parlamentaria, se consigue mayor eficiencia mediante la existencia de un personal funcionario especializado en el trabajo parlamentario. GARCÍA-ESCUDERO destaca, en este sentido, que la autonomía de personal responde a un doble fundamento, teórico y práctico. El fundamento teórico deriva del principio de separación de poderes, mientras que el fundamento práctico estriba, en cambio, en la conveniencia de que exista un personal funcionario con una cualificación específica, dada la especial naturaleza del trabajo parlamentario. GARCÍA-ESCUDERO MÁRQUEZ, P. (1998): "Artículo 72.1: autonomía funcional de las cámaras: reglamentaria, presupuestaria y de personal”, en Comentarios a la Constitución Española, ALZAGA VILLAAMIL, O., (dir.), vol. VI: 423. Madrid: Cortes Generales, Edersa.
} 
Por tanto, es esa la argumentación por la que la Constitución, en su art. 72 CE, relaciona la autonomía en materia de personal con la autonomía reglamentaria y presupuestaria, así como suelen hacer los diversos EE.AA, y que analizamos en la materia referida en el epígrafe quinto de este artículo.

La autonomía en materia de personal incide en la organización y funcionamiento de los propios Parlamentos autonómicos de las CC.AA.

De modo análogo como la autonomía presupuestaria consigue la «independencia» respecto al Poder Ejecutivo en cuánto a los medios materiales; con la autonomía en materia de personal se consigue que los medios personales necesarios no dependan de ningún otro Poder. De esta forma, esta autonormatividad parlamentaria en materia de personal se configura como autonomía e independencia de las Asambleas Parlamentarias en la elaboración de sus propias normas reguladoras del personal que presta sus servicios profesionales en las mismas.

En consecuencia, vemos la importancia que adquiere el hecho de que estos Parlamentos autonómicos ostenten la facultad normativa para aprobar sus EE.PP con rango de ley, pues es, precisamente el rango legal de dicha norma la que establecerá de forma rotunda su «independencia» respecto a determinados ámbitos normativos estatales y competenciales como se recogen en las conclusiones de este estudio.

\section{REGULACIÓN EN LA CONSTITUCIÓN ESPAÑOLA}

El art. 72 CE entiende que es fundamental la existencia de un personal propio para las Cortes Generales, y ello en base a lo siguiente:

1. Se afianza la separación de poderes, pues al ser el personal diferente, se consolida la independencia del Poder Legislativo sin detrimento de que el régimen jurídico que regule a unos y otros colectivos se inspiren en principios comunes, lo que contribuye a que dichos regímenes sean parecidos.

2. La especialidad de la Administración parlamentaria debida a su naturaleza específica de acuerdo con las funciones parlamentarias (legislativa, de control, de impulso) y la función administrativa auxiliar, que debe desarrollar para la realización de las primeras, exigen de los funcionarios parlamentarios una cualificación determinada y completamente diferente de las del resto de los funcionarios de la Administración pública ${ }^{3}$.

Si bien esta especial cualificación justifica «desde siempre» un conjunto normativo propio, no es menos cierto que, en aras de la igualdad, preconizada por la Constitución española, fundamentalmente, y por el resto de la legislación en su desarrollo, hacen que los cuadros normativos de la Administración pública y de la Administración parlamentaria hayan iniciado un proceso de convergencia donde pudiera decirse que la autonomía parlamentaria en gestión de personal sea un vestigio histórico.

Sin embargo, la autonomía en gestión de personal, y administrativa, en general, de las Cortes Generales y Asambleas Legislativas de las CC.AA goza de buena salud. Ejemplo claro de esta autonomía es el EPCG al remitirse a determinada legislación de forma supletoria (relativa a procedimiento administrativo) y a otras no; facultad que ostentan las cámaras en base precisamente a su autonomía administrativa. (JIMÉNEZ, 1984: 693). De hecho, el art. 72.1 CE establece la capacidad de autonormación plena sobre el personal a su servicio sin ningún tipo de limitación, ni analogía al del resto de los funcionarios públicos.

En el mismo sentido, el EBEP establece que sus disposiciones sólo se aplicarán directamente cuando así lo disponga su legislación específica, entre otros, al personal funcionario de las Cortes Generales y de las Asambleas Legislativas de las CC.AA ${ }^{4}$.

En conclusión, es lógico que la Constitución no haga mención a la función pública de los Parlamentos autonómicos de las CC.AA, pues incluso la creación de estas CC.AA no es una cuestión imperativa establecida por la Carta magna; pero si es conveniente resaltar que cuando el art. 72.1 CE afirma que "las Cámaras establecen sus propios Reglamentos, [...] y de común acuerdo, regulan el Estatuto del Personal de las Cortes Generales", no establece ninguna norma expresa a la que estos reglamentos y EPCG deban someterse,

${ }^{3}$ Esta especialidad en la Administración parlamentaria ha motivado que históricamente tengan un sistema propio en materia de personal (selección, retribuciones...). Esta especialidad contrasta con otras especialidades de la Administración pública, DE ESTEBAN, J. y GONZÁLEZ TREVIJANO, P. J. (1994): Curso de Derecho Constitucional español, vol. III, Madrid. Servicio de Publicaciones de la Facultad de Derecho de la Universidad Complutense, 914.

4 Vid. artículo 4 del EBEP. 
por lo que se entiende que los mismos gozan de gran autonomía en la regulación de las competencias que les son propias.

\section{REGULACIÓN AJENA A LA CONSTITUCIÓN ESPAÑOLA}

Tal como hemos expuesto, la autonomía de personal de las Asambleas Legislativas de las CC.AA no viene regulada en la Constitución, al menos, de forma expresa ${ }^{5}$, pudiéndose entender que está inmersa en la misma, dado que esta es una vertiente de la autonomía parlamentaria, globalmente considerada.

Por otra parte, el Tribunal Constitucional señala que «La extensión de la autonomía de las asambleas legislativas de las Comunidades Autónomas viene determinada por el Estatuto de Autonomía de cada una de éstas (ya que no existe, a diferencia de las Cortes Generales, una garantía constitucional al respecto) " ${ }^{6}$, si bien, podríamos entender que dicha autonomía en materia de personal es aplicable en base a cinco argumentos:

1. Por analogía del art. 72 CE pues los ordenamientos estatutarios son similares al constitucional.

2. Los reglamentos parlamentarios, en general, prevén que las Cámaras deben aprobar un estatuto del personal (aunque no concretan, salvo excepciones, el órgano que debe aprobarlo). En tal sentido, la Disposición Adicional Segunda del Reglamento de Parlamento de Andalucía, aprobado por el Pleno del Parlamento de Andalucía, en sesión celebrada los días 18, 19 y 20 de abril de 1995, establece que «los derechos, deberes y situaciones de los funcionarios y resto del personal al servicio del Parlamento de Andalucía serán determinados por un Estatuto de Personal.» En el mismo sentido, ya lo contemplaba la Disposición Final 4. ${ }^{a}$ del Reglamento del Congreso, de 10 de febrero de 1982, y la Disposición Adicional 3. ${ }^{a}$ del Texto refundido del Reglamento del Senado, de 3 de mayo de 1994, respecto a su propio personal.

De modo mimético, lo hacen los restantes reglamentos parlamentarios autonómicos: art. 166 del Reglamento del Parlamento de Asturias, art. 63.2 del Reglamento de las Islas Baleares, art. 71.1 del Reglamento del Parlamento de Canarias, Disposición Final 1. ${ }^{a}$ del Reglamento del Parlamento de Cantabria, Disposición Final $3 .^{a}$ del Reglamento de las Cortes de Castilla y León, art. 72 del Reglamento de las Cortes de Castilla-La Mancha, art. 200.3 del Reglamento del Parlamento de Cataluña, Disposición Adicional 4. ${ }^{a}$ del Parlamento de Galicia, art. 117.1 y 2 del Reglamento del Parlamento de Extremadura, art. 49 f), 87 y Disposición Transitoria $3{ }^{a}$ del Reglamento de la Asamblea de Madrid, art. 78.3 y Disposición Transitoria 2. ${ }^{a}$ de la Asamblea Regional de Murcia, art. 71.1 y Disposición Adicional 3. ${ }^{a}$, apdos. 1 y 2 del Reglamento del Parlamento de Navarra, arts. 57.2 y 72 del Reglamento del Parlamento del País Vasco, art. 164 del Reglamento del Parlamento de la Rioja y art. 110 del Reglamento de las Cortes Valencianas.

3. En otros casos, son los propios EE.AA los que recogen esta atribución para sus Asambleas Parlamentarias. Son los correspondientes a las CC.AA de Aragón, Castilla y León, Cataluña, Extremadura, La Rioja, País Vasco, Principado de Asturias y Región de Murcia.

Es decir, sea por vía estatutaria o a través de los propios reglamentos de las Asambleas Parlamentarias, se está reconociendo la autonomía de personal como algo esencial de la autonomía parlamentaria pues en la mayoría de los diversos EE.AA se establecen la autonomía reglamentaria de sus respectivas cámaras, y los reglamentos de estas, a su vez, reconocen la autonomía de personal como una vertiente de la reglamentaria.

A mayor abundamiento de lo anterior, consideramos la autonomía parlamentaria de las asambleas legislativas y su capacidad autoorganizativa como premisa básica para su autoregulación normativa. No obstan-

${ }^{5}$ Sólo ocho EE.AA contienen la precisión de la aprobación autónoma de sus respectivos EE.PP por la respectiva Asamblea; son los de Aragón, Castilla y León, Cataluña, Extremadura, La Rioja, País Vasco, Principado de Asturias y Región de Murcia (Ley Orgánica 5/2007, de 20 de abril, de reforma del Estatuto de Autonomía de Aragón, Ley Orgánica 14/2007, de 30 de noviembre, de reforma del Estatuto de Autonomía de Castilla y León, Ley Orgánica 6/2006, de 19 de julio, de reforma del Estatuto de Autonomía de Cataluña, Ley Orgánica 1/2011, de 28 de enero, de reforma del Estatuto de Autonomía de la Comunidad Autónoma de Extremadura, Ley Orgánica 3/1982, de 9 de junio, de Estatuto de Autonomía de La Rioja, Ley Orgánica 3/1979, de 18 de diciembre, de Estatuto de Autonomía para el País Vasco, Ley Orgánica 7/1981, de 30 de diciembre, de Estatuto de Autonomía para Asturias, y Ley Orgánica 4/1982, de 9 de junio, de Estatuto de Autonomía para la Región de Murcia, respectivamente).

6 STC 179/1989, de 2 de noviembre, FJ $4 .^{\circ}$

En la misma línea, CID VILLAGRASA recoge que las asambleas legislativas autonómicas no reciben directamente de la Constitución su estatus y competencias esenciales, sino de sus EE.AA, en CID VILLAGRASA, B. (2001): "La administración parlamentaria", Asamblea: revista parlamentaria de la Asamblea de Madrid, 5: 126. En el mismo sentido, GARCÍA-ESCUDERO MÁRQUEZ, P. (1998) cit. 393 y ss., y GARCÍA-ESCUDERO MÁRQUEZ, P. (1999): cit., 209. 
te, respecto a la regulación concreta de la autonomía parlamentaria realizada por los EE.AA de las diversas CC.AA, debemos recordar que todos ellos hacen una mención de la misma, ya sea de forma expresa o no, salvo el Estatuto de Autonomía de Castilla-La Mancha.

Véase, en el sentido indicado, el art. 58 de la Ley Orgánica 6/2006, de 19 de julio, de reforma del Estatuto de Autonomía de Cataluña, art. 102 de la Ley Orgánica 2/2007, de 19 de marzo, de reforma del Estatuto de Autonomía para Andalucía, art. 27 de la Ley Orgánica 4/1982, de 9 de junio, de Estatuto de Autonomía para la Región de Murcia, art. 34 de la Ley Orgánica 5/2007, de 20 de abril, de reforma del Estatuto de Autonomía de Aragón y art. 16 de la Ley Orgánica 1/2011, de 28 de enero, de reforma del Estatuto de Autonomía de la Comunidad Autónoma de Extremadura, en los cuales se recogen expresamente el término «autonomía parlamentaria».

En sentido contrario, no se recoge dicha expresión, pero sin embargo se reconoce la autonomía parlamentaria, en el art. 27 de la Ley Orgánica 3/1979, de 18 de diciembre, de Estatuto de Autonomía para el País Vasco, art. 12 de la Ley Orgánica 1/1981, de 6 de abril, de Estatuto de Autonomía para Galicia, art. 28 de la Ley Orgánica 7/1981, de 30 de diciembre, de Estatuto de Autonomía para Asturias, art. 12 de la Ley Orgánica 8/1981, de 30 de diciembre, de Estatuto de Autonomía para Cantabria, art. 18 de la Ley Orgánica 3/1982, de 9 de junio, de Estatuto de Autonomía de La Rioja, art. 25 de la Ley Orgánica 5/1982, de 1 de julio, de Estatuto de Autonomía de la Comunidad Valenciana, art. 12 de la Ley Orgánica 10/1982, de 10 de agosto, de Estatuto de Autonomía de Canarias, art. 16 de la Ley Orgánica 13/1982, de 10 de agosto, de reintegración y amejoramiento del Régimen Foral de Navarra, art. 45 de la Ley Orgánica 1/2007, de 28 de febrero, de reforma del Estatuto de Autonomía de las Illes Balears, art. 12 de la Ley Orgánica 3/1983, de 25 de febrero, de Estatuto de Autonomía de la Asamblea de Madrid y art. 23 de la Ley Orgánica 14/2007, de 30 de noviembre, de reforma del Estatuto de Autonomía de Castilla y León.

Únicamente, tal como adelantábamos antes, el art. 11 de la Ley Orgánica 9/1982, de 10 de agosto, de Estatuto de Autonomía de Castilla-La Mancha, no reserva la autonomía parlamentaria de su parlamento, realizando solo la reserva de dos funciones como son la elección de la Mesa de la Cámara y la fijación del presupuesto de la misma (no encomienda su elaboración, aunque debe sobreentenderse que la misma debe corresponder a dicho Órgano Legislativo). Ni siquiera, cuando en los artículos 10, 11 o 21 establece determinada regulación como reservada para el reglamento parlamentario, determina la mayoría de votos necesarios para su aprobación.

Pero ¿qué ocurre en este caso ${ }^{7}$ en el que el estatuto de autonomía tampoco recoge la autonomía reglamentaria? La Doctrina entiende que dicha vertiente está incluida en la autonomía parlamentaria según el modelo parlamentario que preconiza la Constitución, y que no es necesaria una atribución expresa, sin embargo, ¿no entiende lo mismo con la autonomía en materia de personal?

La Doctrina tampoco se plantea si esta facultad no es inherente a la autonomía parlamentaria lato sensu, lo que ocurre es que es diferente si está recogida, o no, en el estatuto de autonomía respectivo tal vertiente, en orden a la posición en el sistema de fuentes del Derecho de la norma reguladora del personal, en relación, igualmente, a lo señalado por el Tribunal Constitucional ${ }^{8}$, y desde nuestro punto de vista, será decisivo en la configuración de dicha autonomía como competencia exclusiva de la propia cámara.

4. A los efectos del control de constitucionalidad, se les da el mismo tratamiento a los reglamentos de las Asambleas Legislativas de las CC.AA que a los de las Cortes Generales, tanto para los actos de ley ${ }^{9}$ como para los actos sin valor de ley ${ }^{10}$.

5. Por la declaración del Tribunal Constitucional, se considera posible la aplicación supletoria del EPCG a los funcionarios de los Parlamentos autonómicos ${ }^{11}$.

\footnotetext{
7 Ley Orgánica 9/1982, de 10 de agosto, de Estatuto de Autonomía de Castilla-La Mancha no establece stricto sensu una reserva reglamentaria a favor de su cámara legislativa, pues únicamente dice que un reglamento establecerá, precisará, regulará... pero no establece quien ha de aprobarlo y menos aún la mayoría necesaria para dicha aprobación.

8 "La extensión de la autonomía de las Asambleas legislativas de las Comunidades Autónomas viene determinada por el Estatuto de cada una de éstas" (STC 179/1989, de 2 de noviembre, FJ 4. ${ }^{\circ}$ ).

9 Artículo 27.2.d) LOTC.

10 Artículo 42 LOTC.

11 ATC 241/1984, de 11 de abril (Sala 1. ${ }^{a}$, Sección 2. ${ }^{a}$ ), FJ 2. ${ }^{\circ}$ b), con ocasión del recurso de amparo presentado contra la resolución de la Presidencia de las Cortes de Castilla y León, establece que «...hay que tener en cuenta que si bien, por ahora, las Cortes de Castilla y León no tienen aprobado su Reglamento ni tampoco el Estatuto del personal a su servicio, de acuerdo con el art. 1 de las Normas Provisionales de Organización y Funcionamiento de dicha Asamblea legislativa (...) se aplica supletoriamente el Reglamento del Congreso de los Diputados en tanto se proceda a la mencionada aprobación» (...) «En virtud de esa remisión es aplicable también
} 
A pesar de que la autonomía en materia de personal de las cámaras parlamentarias autonómicas no tenga su raíz directa en la Constitución, no quiere decir por ello, que esté limitada por sus propios EE.AA, sino todo lo contrario, pues desde nuestro punto de vista, los EE.AA no limitarían la autonomía de personal de sus cámaras legislativas, sino que la ampararía y atribuiría. Únicamente, podríamos entender unos EE.AA limitadores de dicha capacidad autonormadora si es en sentido negativo, es decir, en aquellos EE.AA en que, precisamente por su falta de regulación, no haga alusión a dicha competencia de su Cámara legislativa ${ }^{12}$.

En conclusión, a las Administraciones parlamentarias se les dota de los medios personales necesarios, tal como expresamente prevén los respectivos reglamentos parlamentarios de las Asambleas Legislativas de las $\mathrm{CC}_{\mathrm{A}} \mathrm{A}^{13}$. En relación con ello, es la propia cámara legislativa la que, a través de los procedimientos establecidos, aprueba diversas normas como son el reglamento parlamentario ${ }^{14} \mathrm{y}$ el estatuto del personal, entre otras, siendo esta última la encargada de regular los medios personales con que se dota a la Asamblea Legislativa, como son los derechos, deberes y situaciones de los funcionarios y resto del personal al servicio de la misma, sin perjuicio de las competencias que las propias Cámaras, a través de sus normas (reglamento parlamentario y estatuto del personal, fundamentalmente) atribuyen a sus Mesas, como órganos rectores, siendo común a todos ellos la atribución a la Mesa de la aprobación de la composición y naturaleza de la plantilla de personal de la Cámara, la selección y nombramiento de este. En tal sentido, podemos citar los arts. 28.1.3. ${ }^{\circ}$ de los reglamentos parlamentarios de Andalucía, 29.1.i) de Aragón, 37.1.f) de Asturias, 71.2 de Canarias, 33.1.g) de Cantabria, 27.1.3. ${ }^{\circ}$ de Castilla y León, 32.1.9. ${ }^{a}$ de Castilla-La Mancha, 29.3.i) de Cataluña, 49.5 de Extremadura, 49.1.f) de Madrid, 44.e) de Murcia, 28.1.f) de La Rioja, 34.1.Cuarto de las Cortes Valencianas; suponiendo excepciones a lo indicado anteriormente los reglamentos parlamentarios de las Islas Baleares, Canarias, Galicia, Navarra y País Vasco que no establecen de forma específica la competencia de la aprobación de las respectivas plantillas de personal.

\section{LA JURISPRUDENCIA CONSTITUCIONAL Y DEL TRIBUNAL SUPREMO RELATIVAA LA COM- PETENCIA NORMATIVA DE LAS ASAMBLEAS LEGISLATIVAS EN RELACIÓN CON SUS ES- TATUTOS DEL PERSONAL ${ }^{15}$}

De la misma forma que se ha llevado a cabo por nuestro Tribunal Constitucional el encuadramiento material del EPCG, debe hacerlo respecto del resto de EE.PP sobre los cuales debe pronunciarse.

En efecto, es lo que el Tribunal Constitucional ha hecho en las sentencias, que analizamos a continuación, respecto a los EE.PP sometidos al análisis del Tribunal, es decir, ha realizado el encuadramiento material de estos EE.PP como un prius antes de examinar el contenido de los mismos.

En tal sentido, podemos citar la siguiente Jurisprudencia:

Respecto al ATC 296/1985, de 8 de mayo, no obstante, no hace mención a la cuestión de la vinculación del Estatuto de Régimen y Gobierno Interior del Parlamento de Navarra con la LORAFNA, norma institucional básica de la Comunidad Foral de Navarra, sino que únicamente el Tribunal entiende que el

subsidiariamente a las Cortes de Castilla y León el referido Estatuto-aprobado por las Mesas del Congreso de los Diputados y del Senado-» (...)

12 Para GARCÍA-ESCUDERO la autonomía de personal de los parlamentos autonómicos estaría limitada por los respectivos EE.AA, GARCÍA-ESCUDERO MÁRQUEZ, P. (1999), cit., 218.

13 Así lo disponen los siguientes preceptos: art. 60 del Reglamento del Parlamento de Andalucía, art. 272 del Reglamento del Parlamento de Asturias, art. 63.1 del Reglamento de las Islas Baleares, art. 70.1 del Reglamento del Parlamento de Canarias, art. 62 del Reglamento del Parlamento de Cantabria, art. 59.1 del Reglamento de las Cortes de Castilla y León, art. 71 del Reglamento de las Cortes de Castilla-La Mancha, art. 25.1 del Reglamento del Parlamento de Cataluña, arts. 40.1 y 116.2 del Reglamento del Parlamento de Extremadura, art. 87 del Reglamento de la Asamblea de Madrid, art. 78.2 del Reglamento de la Asamblea Regional de Murcia, art. 70 del Reglamento del Parlamento de Navarra, art. 28.1 del Reglamento del Parlamento del País Vasco, Disposición Adicional 4. ${ }^{a}$ del Parlamento de Galicia y art. 108.2 del Reglamento de las Cortes Valencianas.

14 Si bien, el reglamento parlamentario no tiene como finalidad la Administración parlamentaria, stricto sensu, sino el parlamento como órgano constitucional, ya que es la norma «mediante la cual se desarrolla la materia parlamentaria constitucionalmente establecida, disciplinándose al mismo tiempo los trabajos internos de las Cámaras» (Definición de reglamento parlamentario de PÉREZ ROYO, J. (1994): Curso de Derecho Constitucional. Madrid. Marcial Pons, 458), no cabe duda alguna, que la propia Administración parlamentaria ha de estar sujeta a la misma.

15 La jurisprudencia del Tribunal Constitucional y del Tribunal Supremo que se recoge en este epígrafe se refiere únicamente a la que establece como vínculo específico la incardinación de los estatutos del personal con sus respectivos EE.AA y no a cualquier otra relacionada con otros extremos que son ajenos, a la autonomía normativa de los Parlamentos autonómicos, objeto de este artículo. 
acto impugnado tiene el carácter de disposición general, al estar integrado en un Estatuto con valor de Ley (aunque emanado de la Mesa de la Cámara, como vemos en el subepígrafe siguiente), por lo que no está comprendido en la hipótesis del art. 42 LOTC.

EI ATC 296/1985, de 8 de mayo, es el primer pronunciamiento jurisprudencial del Tribunal Constitucional relativo a las normas de personal de las cámaras autonómicas, y hubiera cabido pensar, en su momento, que el reconocimiento del Tribunal respecto al Estatuto navarro, como norma con valor de ley, debería ser aplicable a los restantes EE.PP de las cámaras legislativas autonómicas, fundamentalmente, porque tal como hemos indicado en el párrafo anterior, la sentencia no establece como premisa ninguna relación directa entre el Estatuto de Autonomía navarro y el Estatuto de Régimen y Gobierno Interior de dicho Parlamento, y dado, por otro lado, que el citado Estatuto tiene su fundamento en el Reglamento parlamentario navarro, en tanto que la LORAFNA, no contiene previsión alguna al respecto, por lo que no puede predicarse el rasgo de primariedad.

La STC 183/2012, de 17 de octubre, en relación con la naturaleza de las Normas de Gobierno Interior del Parlamento de Canarias, se remite a la posición que en el sistema de fuentes ocupa el EPCG en relación con el pronunciamiento realizado en la STC anterior (139/1988, de 8 de julio), es decir, vincula el Estatuto del personal canario con su respectivo Estatuto de Autonomía, al igual que la STC 139/1988 vinculaba el EPCG con la Constitución.

Es patente el cambio de parecer del Tribunal Constitucional y que, en aquel momento histórico, se debió a que, si no hubiera entendido entonces que la citada norma era susceptible de control de constitucionalidad, no hubiera resultado posible su fiscalización jurisdiccional ante ninguna otra instancia, pues al momento de resolverse el recurso de amparo que originó dicho auto, la Ley Orgánica 6/1985, del Poder Judicial, de 1 de julio, todavía no había entrado en vigor.

Respecto al resto de la jurisprudencia, si se contempla el establecimiento de una conexión entre los EE.PP y la norma fundamental; en unos casos, con la Constitución (en el caso del EPCG), como norma suprema; en otros casos, con los respectivos EE.AA, como normas institucionales básicas de las CC.AA.

En tal sentido, la STS, de 20 de enero de 1987 (RJ 1987/317), establece en el FJ $3 .^{\circ}$ que el EPCG es el resultado de la reserva que a su favor hace la Constitución:

[...] dicho Estatuto es el resultado de la autonomía institucional de ambas Cámaras reconocida en el artículo 72.1 de la Constitución Española, y como tal, se reconoce a aquéllas la facultad de regular el Estatuto del Personal de las Cortes Generales; estos Estatutos, como reguladores de la denominada función pública, tienen una indudable reserva constitucional a la Ley [...]

La STC 139/1988, de 8 de julio, establece como premisa básica del rango de ley del EPCG que el mismo tenga una vinculación directa con la Constitución, que exista una reserva a favor de la norma (FJ 2. ${ }^{\circ}$ ):

[...] baste con retener que la Constitución, en su art. 72.1, establece una reserva formal y material a favor del «Estatuto del Personal de las Cortes generales», de manera que ese Estatuto aparece como una norma directamente vinculada a la Constitución, es decir, como una norma primaria -o acto normativo primaria- que, por ello mismo, determina que la regulación a él encomendada quede fuera del alcance de cualquier otra norma jurídica. Así, pues, el Estatuto del Personal de las Cortes Generales, por imperativo constitucional, goza de una efectiva fuerza de Ley, al menos en su vertiente pasiva, por cuanto que ninguna otra norma del ordenamiento puede proceder a la regulación que a él le ha sido reservada y en exclusiva atribuida por la Constitución [...]

El ATS de 10 de octubre de 1989 (RJ 1989l6857), continúa en la misma línea que la jurisprudencia constitucional de la sentencia anterior, al considerar, en el FJ $3 .^{\circ}$, el carácter reglamentario de las normas del Parlamento navarro, por no tener punto de conexión con el Estatuto de Autonomía de Navarra:

Y tampoco puede traerse a colación el Estatuto del Personal de las Cortes Generales, que sí se incardina directamente en la Constitución (art. 72.1) y por ello le cabe el calificativo de norma de carácter primario, pues el Estatuto de Régimen y Gobierno Interior del Parlamento de Navarra no tiene punto de conexión con la LORAFNA sino que deriva del Reglamento del Parlamento de Navarra [...].

En el mismo sentido, en FJ $4 .^{\circ}$ de la STS, de 26 de septiembre de 1994 (RJ 199417339), se vincula el EPCG con la Constitución: 
[...] no se puede identificar con un reglamento propiamente dicho, sino, más bien, se trata de una auténtica Ley, en la medida que tales normas reglamentarias proceden de los órganos legislativos y enlazan directamente con las normas constitucionales -art. 72.2-, de lo que se infiere, como conclusión, que son normas primarias, sólo justiciables ante el Tribunal Constitucional.

La STS ${ }^{16}$, de 21 de diciembre de 2007 (9068/2007), si bien, no nombra de forma expresa la reserva competencial, si se refiere a la autonomía singular que disfrutan las Cámaras que les permiten apartarse del régimen de personal que se regula con carácter general. En tal sentido, el FJ 4 dice que:

Ninguna duda cabe sobre la especial posición que la Constitución asigna al Congreso de los Diputados y al Senado, ni tampoco sobre las características que distinguen a la Administración Parlamentaria precisamente porque está al servicio de las Cortes Generales y, por tanto, de las funciones que éstas desempeñan. De ahí la singular autonomía que disfrutan las Cámaras, en virtud de lo dispuesto por el artículo 72 de la misma Constitución. Parece igualmente claro que esas señaladas características pueden llegar a justificar, en algunos casos y respecto de aspectos concretos del régimen del personal que presta servicio para ellas, soluciones particulares que se aparten de lo establecido con carácter general para los funcionarios públicos o para quienes trabajan para las Administraciones en razón de un contrato laboral.

En la misma línea, la STC 183/2012, de 17 de octubre, en la que se examina las Normas de Gobierno Interior del Parlamento de Canarias, en relación a la reserva que pueda hacer el Estatuto de Autonomía de Canarias, también con carácter negativo, pues en este caso, de modo análogo al ATS anterior, afirma, en el FJ $5 .^{\circ}$, que:

[...] podemos ya descartar que las Normas de gobierno interior y, por tanto, la disposición transitoria primera impugnada en esta cuestión de inconstitucionalidad tengan fuerza de Ley. No existiendo una reserva en el Estatuto de Autonomía de Canarias a favor del estatuto del personal del Parlamento no puede predicarse de las Normas de gobierno interior su carácter primario o directamente derivado del Estatuto de Autonomía, por lo que carecen de la condición de norma con fuerza y valor de Ley y, por tanto, del carácter de «acto con fuerza de Ley» [...].

\section{CONCLUSIONES}

Es sustancialmente diferente si dicha facultad o competencia está recogida de forma expresa, o no, en el Estatuto de Autonomía respectivo, en orden a la posición en el sistema de fuentes del Derecho de la norma reguladora del personal, en relación, igualmente, a lo señalado por el Tribunal Constitucional ${ }^{17}$; es decir, será uno de los requisitos que se debe tener en cuenta si se pretende que la norma parlamentaria en materia de personal tenga rango legal o reglamentario.

Consecuencia de ello es que, la previsión estatutaria constituye la condición básica y primera (pero, no única, ni suficiente) para que dichos EE.PP ostenten rango legal. Consecuentemente con lo expuesto, el reconocimiento de una competencia exclusiva y específica recogida en los EE.AA, a favor de sus Asambleas Parlamentarias, no constituye, per se, que la misma funcione de forma automática para habilitar el rango legal de esta tipología de normas.

Los EE.PP, considerados como leyes autonómicas, implican una operación de encuadramiento material de las mismas. Es decir, se exige una vinculación del estatuto del personal en cuestión con un título competencial habilitante para la aprobación del mismo como norma legal, siendo su ajuste o no al sistema de distribución competencial el que indicará, consecuentemente, su correcta posición en el ordenamiento constitucional. Este encuadramiento dará como resultado la intensidad o capacidad de las cámaras legislativas para regular la función pública parlamentaria a través de los EE.PP.

En otras palabras, las consecuencias relativas a la naturaleza jurídica de los EE.PP originadas por la diferenciación de origen (previsión por los EE.AA o por los reglamentos parlamentarios) serán importantes,

16 STS 9068/2007, consecuencia del recurso contencioso-administrativo núm. 149-2004, interpuesto por don Clemente, funcionario del Cuerpo de Ujieres de las Cortes Generales, con destino en la Unidad de Servicios Generales de la Dirección de Gobierno Interior del Senado, contra la Resolución de la Mesa de la Diputación Permanente del Senado de 1 de abril de 2004.

17 STC 179/1989, de 2 de noviembre, FJ 4. ${ }^{\circ}$. 
pues si podemos afirmar el rasgo de primariedad de los EE.PP que tengan su origen en sus respectivos EE.AA (en su caso), no podemos predicar lo mismo respecto de aquellos estatutos cuya única previsión son sus reglamentos parlamentarios, como hemos comprobado con la jurisprudencia que hemos analizado.

En definitiva, respecto a las competencias normativas que han de ostentar las Asambleas Legislativas autonómicas para que los EE.PP, aprobados por las referidas cámaras, tengan rango de ley, se exige que haya una conexión o vinculación directa con el Estatuto de autonomía respectivo.

Sin perjuicio de todo lo anterior, recordemos que, si bien es necesario, como ha quedado suficientemente reflejado, un título competencial que habilite al legislador autonómico para aprobar, como norma legal, el estatuto del personal, dicho título competencial se encuentra con unos límites competenciales y unos títulos transversales, que complican la labor de las cámaras autonómicas en el referido propósito.

En resumen, se podría pensar, prima facie, en considerar que los EE.PP de los Parlamentos autonómicos y el EPCG tienen el mismo rango normativo, y otorgarles, por tanto, el rango normativo de fuerza y valor de ley, y que, consecuentemente, aquellos sean justiciables en el Tribunal Constitucional, a través del art. 27 LOTC. Pero, como hemos ido exponiendo a lo largo de este trabajo, debemos tener en cuenta el ordenamiento jurídico autonómico, la distribución competencial y, por tanto, los sistemas de fuentes de las diversas CC.AA, que poseen particularidades que impiden hacer una posición genérica de los EE.PP de las cámaras parlamentarias autonómica, de forma general, ya que cada Comunidad Autónoma tiene, en principio, un ordenamiento jurídico y sistema de fuentes del derecho propios.

\section{REFERENCIAS BIBLIOGRÁFICAS}

BLANCO HERRANZ, F. J. (2002): "Modernización de los parlamentos: nuevas herramientas de gestión para su organización y funcionamiento", en El Parlamento del siglo XXI, VIII Jornadas de la Asociación Española de Letrados de Parlamentos: 157-187. Madrid: Tecnos.

CID VILLAGRASA, B. (2001): "La administración parlamentaria". Asamblea: revista parlamentaria de la Asamblea de Madrid, 5: 125-150.

DE ESTEBAN, J. y GONZÁLEZ TREVIJANO, P. J. (1994): Curso de Derecho Constitucional español, vol. III, Madrid. Servicio de Publicaciones de la Facultad de Derecho de la Universidad Complutense.

FERNÁNDEZ-VIAGAS BARTOLOMÉ, P. (2008): El poder legislativo entre la política y el derecho. Cizur Menor (Navarra): Aranzadi.

GARCÍA-ESCUDERO MÁRQUEZ, P. (1998): "Artículo 72.1: autonomía funcional de las cámaras: reglamentaria, presupuestaria y de personal", en Comentarios a la Constitución Española, ALZAGA VILLAAMIL, O., (dir.), vol. VI: 389-429. Madrid: Cortes Generales, Edersa.

- (1999): "Actos de la administración parlamentaria", en Los actos del parlamento: 205-274. Vitoria-Gasteiz. Parlamento Vasco.

GUILLEM CARRAU, J. (2011): "Ejes de la función pública parlamentaria y el principio del buen gobierno", Cuadernos Manuel Giménez Abad, 2: 70-81.

JIMÉNEZ ASENSIO, R. (1984): "El estatuto de personal del Parlamento Vasco: notas en torno a su naturaleza y control jurisdiccional", en I Jornadas de Derecho Parlamentario, vol. II: 687-713. Madrid. Congreso de los Diputados.

MARTÍNEZ CORRAL, J. A. y VISIEDO MAZÓN, F. J. (2008): "El Estatuto Básico del Empleado Público y su posible aplicación a los Parlamentos autonómicos". Asamblea: revista parlamentaria de la Asamblea de Madrid, 19: 93-132.

- (2009): "El régimen del personal al servicio de los parlamentos autonómicos, heterogeneidad o fragmentación: la conveniencia de promover una Conferencia de Cooperación de Administraciones Parlamentarias", Corts: anuario de Derecho Parlamentario, 22: 145-178.

MURO I BAS, X. (2009): "Notas en torno a las normas internas del Parlamento en materia de personal", Corts: anuario de Derecho Parlamentario, 22: 209-228.

PÉREZ ROYO, J. (1994): Curso de Derecho Constitucional. Madrid. Marcial Pons.

PÉREZ SERRANO, N. (1976): Tratado de Derecho Político. Madrid. Civitas.

SARMIENTO MÉNDEZ, X. A. (2009): "La función pública parlamentaria y su plasmación legislativa en Galicia", Corts: anuario de Derecho Parlamentario, 22: 251-272.

SERRANO RUIZ, E. (2006): "Los funcionarios de la Administración parlamentaria en España", Asamblea: revista parlamentaria de la Asamblea de Madrid, 15: 143-164.

TUDELA ARANDA, J. (2008): El parlamento necesario: parlamento y democracia en el siglo XXI. Madrid. Congreso de los Diputados.

- (2011): "La Administración parlamentaria en la encrucijada de la renovación", Corts: anuario de Derecho Parlamentario, 23: 157-191. 